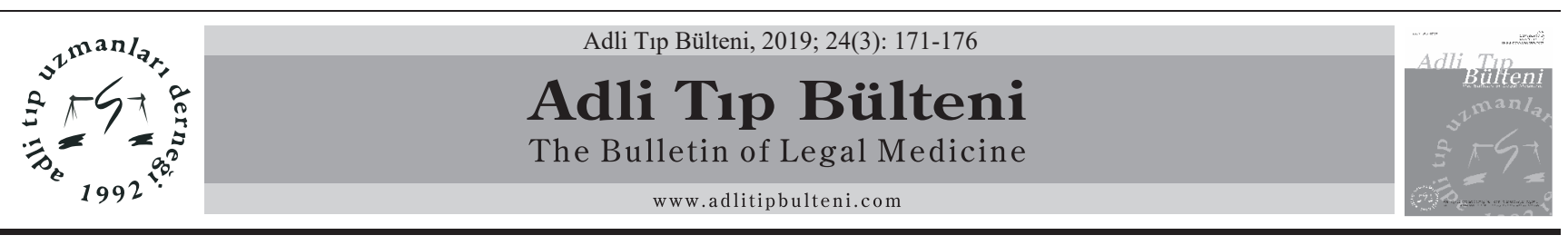

ARAŞTIRMA / RESEARCH ARTICLE

\title{
Postmortem Kalp Okulu
}

\author{
Postmortem Heart School
}

\section{Volkan Zeybek*, Ayşe Kurtuluş, Cüneyt Orhan Kara, Asuman Kaftan, İsmail Doğu Kılıç, Gökhan Ersoy, Kemalettin Acar}

\begin{abstract}
Amaç
Giriş: Ani kardiyak ölümlerde, otopsi kesin ölüm nedenini belirlemede ilk ve tek seçenektir. Avrupa Kardiyovasküler Patoloji Birliği tarafından, ani ölüm/ ani kardiyak ölüm tanımlamaları, otopsi prosedürü ve yapılması gereken laboratuvar tetkiklerinin açıklandığı, ani kardiyak ölümlerin otopsisi için güncellenmiş kılavuz yayınlanmıştır. Çalışmamızda bu kılavuzdan hareket edilerek, konu hakkında standart oluşturma çabasına yönelik temel multidisipliner teorik bilgi aktarımı ve kalp diseksiyonu beceri eğitimini de içeren, iki günlük bir eğitim şeklinde planlanan ve "Postmortem Kalp Okulu" adı altında uygulamaya konulan bir kurs programının değerlendirilmesi amaçlanmıştır.

Gereç ve Yöntem: Kurs, teorik ve uygulama eğitiminin yapıldığı iki kısım olarak planlamıştır. Katılan adli tıp uzmanlık öğrencilerinin bilgi düzeyinde, öğrenme hedeflerine ulaşıp ulaşamadıklarını saptamak amacıyla, kursun başlangıcı ve bitişinde kullanılmak üzere öğrenme hedeflerine uygun olarak 10 soruluk bir test oluşturulmuştur. Kursiyerlerin, kursa ait deneyimleri South East Thames kısa interaktif kurs değerlendirme ölçeği ile değerlendirilmiştir. Bu ölçeğin sonuna kursiyerlerin beceri kazanımlarına yönelik düşüncelerini öğrenmek üzere iki madde eklenmiş ve ayrıca nitel değerlendirmede kullanılmak üzere kursiyerlerin kurs hakkındaki düşüncelerini yazacakları bir kısım oluşturulmuştur.

Bulgular: Katılımcıların ön test ve son test ortalamaları karşılaştırıldığında, eğitim öncesine göre istatistiksel olarak anlamlı şekilde yükseldiği saptanmıştır. Kurs değerlendirme ölçeği sonuçları incelendiğinde; katılımcıların büyük çoğunluğunun eğitim sürecinden memnun kaldığı ve eğitim sonrasında kalp diseksiyonu becerisi açısından kendilerini yeterli hissettikleri anlaşılmıştır.

Sonuç: Adli tıp uzmanlık öğrencilerine uygulanan Postmortem Kalp Okulu eğitiminin, ani kardiyak ölüm ve kalp diseksiyonu bilgi ve beceri düzeylerine kısa dönemde olumlu etkisinin olduğu belirlenmiştir. Bu eğitimin uzun dönem etkilerinin, ileride yapılacak diğer kurslarla birlikte daha çok katılımcı sayılarıyla beraber değerlendirilmesi planlanmıştır.
\end{abstract}

Anahtar Kelimeler: Ani; Kardiyak; Ölüm; Kalp; Diseksiyonu; Mezuniyet; Sonrası Tıp Eğitimi.

\section{Abstract}

Objective: Autopsy is the first and only choice in determining cause of death in sudden cardiac death. An updated guideline has been published by the Association for European Cardiovascular Pathology for describing sudden death/ sudden cardiac death, autopsy procedure and laboratory tests to be performed. The aim of this study is to evaluate postmortem cardiac school program, which is planned based on this guideline.

Materials and Methods: Course program has theoretical and practical training. A 10-question test was developed for the participants in accordance with their learning objectives to be used at the beginning and end of course. Experiences of trainees were evaluated by South East Thames short interactive course evaluation scale. Two items were added to learn the thoughts of participants on the skills acquisition. A section was formed in which trainees could write their thoughts about course in order to be used in qualitative evaluation.

Results: The pre-test and post-test averages of participants were compared, there was statistically significant increase compared to pre-training. The results of course evaluation scale are examined; it was understood that the majority of participants were satisfied with education process and they felt sufficient in terms of ability to dissection of heart after training.

Conclusion: Postmortem Heart School education applied to forensic medicine students has a positive effect on knowledge and skill levels of sudden cardiac death and heart dissection in short term. It is planned to evaluate the long-term effects of this training together with the number of participants in addition to other courses.

Keywords: Sudden; Cardiac; Death; Heart Dissection; Postgraduate; Medical Education

\section{DOI: $10.17986 / \mathrm{blm} .2019252260$}

Volkan Zeybek: Dr. Öğr. Üyesi, Pamukkale Üniversitesi Tıp Fakültesi Adli Tıp Anabilim Dalı, Denizli Eposta: vzeybek@pau.edu.tr ORCID iD: https://orcid.org/0000-0002-8079-2671

Ayşe Kurtuluş: Doç. Dr., Pamukkale Üniversitesi Tıp Fakültesi Adli Tıp Anabilim Dalı, Denizli

Eposta: akurtulus@pau.edu.tr

ORCID iD: https://orcid.org/0000-0002-0592-585X

Cüneyt Orhan Kara: Prof. Dr., Pamukkale Üniversitesi Tıp Fakültesi Kulak Burun Boğaz Hastalıkları Anabilim Dalı, Denizli

Eposta: cokara@pau.edu.tr

ORCID iD: https://orcid.org/ 0000-0003-2219-4283

Asuman Kaftan: Prof. Dr., Pamukkale Üniversitesi Tip Fakültesi Kardiyoloji Anabilim Dalı, Denizli

Eposta: akaftan@pau.edu.tr

ORCID iD: https://orcid.org/ 0000-0002-5073-7348

İsmail Doğu Kılıç: Doç. Dr., Pamukkale Üniversitesi Tıp Fakültesi Kardiyoloji Anabilim Dalı, Denizli

Eposta: idogukiliç@pau.edu.tr

ORCID iD: https://orcid.org/ 0000-0002-5270-3897

Gökhan Ersoy: Doç. Dr., İstanbul Üniversitesi Adli Tıp Enstitüsü, İstanbul

Eposta: gersoy@istanbul.edu.tr

ORCID iD: https://orcid.org/ 0000-0002-4594-7172

Kemalettin Acar: Prof. Dr., Pamukkale Üniversitesi Tıp Fakültesi Adli Tıp Anabilim Dalı, Denizli

Eposta:kacar@pau.edu.tr

ORCID iD: https://orcid.org/0000-0002-0200-4764

Bildirimler/ Acknowledgement

Yazarlar bu makale ile ilgili herhangi bir çıkar çatışması bildirmemişlerdir.

The authors declare that they have no conflict of interests regarding content of this article.

\section{Finansal Destek/Support Resources}

Yazarlar bu makale ile ilgili herhangi bir finansal destek bildirmemişlerdir.

The Authors report no financial support regarding content of this article.

*Sorumlu Yazar/Corresponding Author:

Geliș: 13.12.2018

Düzeltme: 02.04.2019

Kabul: 08.04.2019

p-ISSN: 1300-865X

e-ISSN: 2149-4533 


\section{Giriş}

Ani ölüm, sağlıklı olarak bilinen kişilerde altta yatan asemptomatik seyreden bir hastalığın sıklıkla ilk belirtisi olarak karşımıza çıkabilir. Böyle durumlarda, otopsi kesin ölüm nedenini belirlemede ilk ve tek seçenektir. Epidemiyolojik verilerin yorumlanmasinda temel problem, ölüm sertifikasyonundaki standardizasyon eksikliği ve ani ölüm ile ani kardiyak ölüm tanımındaki değişkenliktir. Ani kardiyak ölüm, sağlıklı olarak bilinen bir kişide veya ani ölümcül sonucu öngörülmeyen hastalığg olan bir şahısta semptomların başlangıcından itibaren bir saat içinde gerçekleşen kardiyak nedenli, doğal, beklenmeyen, ölümcül olay olarak tanımlanmıştır. Bu tanımlama, acil servislerde veya topluluk içinde görgü tanığı olan pek çok ölümü karşılamaktadır. Ancak, görgü tanığı olmayan, uyku sırasında gerçekleşen ölümler veya ölüm zamanı bilinmeyen buluntu cesetler gibi otopsi yapılması gereken durumlar için tatmin edici bir tanımlama değildir. Bu nedenle ölümden 24 saat öncesine kadar sağlıklı olduğu bilinen bir kişinin ölmesi de ani kardiyak ölüm tanımlamasına eklenmiştir (1-4).

İmplante edilebilir kardiyoverter defibrilatörler, toplum temelli kardiyopulmoner resusitasyon, koroner kalp hastalı̆̆ yönetimi gibi konularda büyük gelişmeler olsa da ani kardiyak ölümler, batı toplumlarında, hala ölümlerin \%15- 25'inin nedenidir. Ayrıca, ani kardiyak ölümler, tüm kardiyovasküler ölümlerin yaklaşık \%50'sini oluşturmaktadır. Son 20-30 yılda Amerika Birleşik Devletleri'nde yılda yaklaşık 230.000- 350.000 ani kardiyak ölüm gerçekleşmiştir $(2,5)$.

Ani ölümlerde, ölüm nedeninin ortaya konması için otopsi yapılması şarttır. Özellikle görgü tanığ1 olmayan ani kardiyak ölümler, adli tıp uzmanları tarafından incelenen ölümler içinde büyük yer kaplamaya devam etmektedir ve bu ölümlerin uygun şekilde tanınması ve belgelendirilmesi büyük önem taşımaktadır. Adli tıp uzmanları, ani ölümün kesin tanısını koymakla sorumludur. Ancak giderek karmaşıklaşan bu göreve yaklaşım biçimlerinde önemli farklılıklar vardır. Ani ölümün araştııılmasıyla ilgili çeşitli kitap bölümleri, kılavuzlar, makaleler düzenlenmiştir. Fakat aynı ülkenin farklı merkezleri arasında bile bu konuda tutarlılık oldukça azdır $(6,7)$. Ülkemiz için de bu durumun büyük ölçüde geçerli olduğu bilinmektedir.

Avrupa Kardiyovasküler Patoloji Birliği tarafından 2017 yılında ani kardiyak ölümlerin otopsisi için güncellenmiş kılavuz yayınlanmıştır. Bu kılavuzda ani ölüm/ ani kardiyak ölüm tanımlamaları, otopsi prosedürü ve yapılması gereken laboratuvar tetkikleri ayrıntılarıyla açıklanmıştır (3). Çalışmamızda bu kılavuzdan hareket edilerek, konu hakkında standart oluşturma çabasına yönelik temel multidisipliner teorik bilgi aktar1mı ve kalp diseksiyonu beceri eğitimini de içeren, iki günlük bir eğitim şeklinde planlanan ve "Postmortem Kalp Okulu" adı altında uygulamaya konulan bir kurs programının değerlendirilmesi amaçlanmıştır. İlk kurs Denizli'de Pamukkale Üniversitesi Tıp Fakültesi (PAÜTF) Adli Tıp Anabilim Dalı'nda 15-16 Eylül 2018 tarihlerinde adli tıp alanında eğitim gören tıpta uzmanlık öğrencilerinden oluşan bir grup ile gerçekleştirilmiştir. Çalışmamızda bu kursun farklı yönlerden değerlendirilmesi yapılmıştır.

\section{Gereç ve Yöntem}

Çalışmaya başlamadan ve kurs hazırlıklarının yapılmakta olduğu esnada Pamukkale Üniversitesi Tıp Fakültesi Girişimsel Olmayan Klinik Araştırmalar Etik Kurulu'na müracaat edilerek etik onay alınmıştır.

Kursun içeriği Avrupa Kardiyovasküler Patoloji Birliği’nin düzenlediği ani kardiyak ölümlerin otopsisi için güncellenmiş kılavuz temel alınarak hazırlanmıştır. Öncelikle kursa ait öğrenme kazanımları belirlenmiştir. Bu öğrenme kazanımlarına göre kurs teorik ve uygulama (beceri kazandırma) eğitiminin yapıldığı iki kısım olarak planlamıştır. Bir buçuk günlük teorik eğitimde ani kardiyak ölümlere genel bakış ve adli tıp yaklaşımı, kalbin anatomisi ve ani kardiyak ölümlerde makroskopik patoloji, ani kardiyak ölümlere kardiyolog bakışı ve ESC s1nıflamaları, girişimsel müdahalede bulunulmuş kalplere yaklaşım, kardiyak patolojilerde histolojik bulgular başlıklı sunumlar yer almıştır. Bu kısımda konuda deneyimli olan adli tıp, kardiyoloji ve patoloji uzmanları görev almıştır. Beceri eğitiminde kursiyerlerin kullanması için, diseksiyonu basamak basamak anlatan bir kalp diseksiyonu rehberi oluşturulmuştur. Diseksiyon uygulamasına başlamadan önce demonstrasyon amaçlı kursiyerlere gösterilmek üzere daha önceden hazırlanmış bulunan 35 dakikalık bir kalp diseksiyon videosu gösterilmiştir. Beceri eğitimi ise her kursiyer bir kalp diseksiyonunu tamamen kendisi yapacak şekilde planlanmıştır. Diseksiyonlar için kursiyer sayısına göre koyun kalbi sağlanmış ve eğitimin bu kısmı Anatomi diseksiyon salonunda, her kursiyere yetecek sayıda diseksiyon araçları temin edilerek gerçekleştirilmiştir.

Kursun duyurusu iki ay öncesinden, mail grubu aracılığıyla yapılmıştır. Kursun düzenlenmesi ve katılımcıların konaklaması için Adli Tıp Uzmanları Derneği’nden (ATUD) destek alınmıştır. Kurs programı tablo 1'de görülmektedir. 
Tablo 1. Postmortem Kalp Okulu Kurs Programı

\section{Gün}

\begin{tabular}{|l|l|}
\hline $9.00-9.30$ & Açılış \\
\hline $9.30-10.00$ & Ön Test \\
\hline $10.00-10.45$ & $\begin{array}{l}\text { Ani Kardiyak Ölümlere Genel Bakış } \\
\text { Ve Adli Tıp Yaklaşımı }\end{array}$ \\
\hline $10.45-11.00$ & Ara \\
\hline $11.00-11.45$ & $\begin{array}{l}\text { Kalbin Anatomisi ve Ani Kardiyak } \\
\text { Ölümlerde Makroskopik Patoloji- } 1\end{array}$ \\
\hline $12.00-13.15$ & Yemek \\
\hline $13.30-14.15$ & $\begin{array}{l}\text { Kalbin Anatomisi Ve Ani Kardiyak } \\
\text { Ölümlerde Makroskopik Patoloji-2 }\end{array}$ \\
\hline $14.15-14.30$ & Ara \\
\hline $14.30-15.15$ & $\begin{array}{l}\text { Ani Kardiyak Ölümlere Kardiyolog } \\
\text { Bakış1 Ve Esc Sinıflamaları }\end{array}$ \\
\hline $15.15-15.30$ & Ara \\
\hline $15.30-16.15$ & $\begin{array}{l}\text { Girişimsel Müdahalede Bulunulmuş } \\
\text { Kalplere Yaklaşım }\end{array}$ \\
\hline $16.15-17.00$ & Günün Değerlendirilmesi \\
\hline $17.00-$ & Sosyal Program \\
\hline $2 . G a n$ & \\
\hline
\end{tabular}

\section{Gün}

\begin{tabular}{|l|l|}
\hline $9.00-9.45$ & $\begin{array}{l}\text { Kardiyak patolojilerde histolojik } \\
\text { bulgular-1 }\end{array}$ \\
\hline $9.45-10.00$ & Ara \\
\hline $10.00-10.45$ & $\begin{array}{l}\text { Kardiyak patolojilerde histolojik } \\
\text { bulgular-2 }\end{array}$ \\
\hline $10.45-11.00$ & Ara \\
\hline $11.00-11.45$ & $\begin{array}{l}\text { Kalp diseksiyonu-1 (Demonstrasyon } \\
\text { videosu eşliğinde diseksiyon sunumu) }\end{array}$ \\
\hline $12.00-13.15$ & Yemek \\
\hline $13.30-14.30$ & Kalp diseksiyonu-2 (Pratik uygulama) \\
\hline $14.30-14.45$ & Ara \\
\hline $14.45-15.45$ & Kalp diseksiyonu-2 (Pratik uygulama) \\
\hline $15.45-16.00$ & Ara \\
\hline $16.00-16.15$ & Son Test \\
\hline $16.15-17.00$ & $\begin{array}{l}\text { Eğitimin Değerlendirilmesi ve Geri } \\
\text { Bildirim }\end{array}$ \\
\hline
\end{tabular}

Kursiyerlerin bilgi düzeyinde öğrenme hedeflerine ulaşıp ulaşamadıklarını saptamak amacıyla, kursun başlangıcı ve bitişinde kullanılmak üzere öğrenme hedeflerine uygun olarak 8'i çoktan seçmeli, 2'si kısa cevaplı 10 soruluk bir test oluşturulmuştur. Kursiyerlerin kursa ait deneyimlerinin de South East Thames (SETh) kısa interaktif kurs değerlendirme ölçeği (Cronbach Alfa Güvenirlik Katsayısı: 0.92) ile değerlendirilmesi planlanmıştır (8). Bu ölçeğin sonuna kursiyerlerin beceri kazanımlarına yönelik düşüncelerini öğrenmek üzere iki madde eklenmiş ve ayrıca nitel değerlendirmede kullanılmak üzere kursiyerlerin kurs hakkındaki düşüncelerini yazacakları bir kısım oluşturulmuştur.

Veriler, SPSS 21.0 paket programı ile değerlendirilmiştir. Ön test, son test puanları arasındaki farklılığın analizinde Student's t-Test kullanılmıştır. Anlamlılık düzeyi $p<0.05$ olarak belirlenmiştir. SETh kısa interaktif kurs değerlendirme ölçeğinden elde edilen sonuçların güvenirliği içinde Cronbach alfa kat sayısı hesaplanmıştır. Nitel değerlendirme içinse yazılı geri bildirimler incelenip, benzer olanlar belli başlıklar altında gruplandırılarak değerlendirilmesi planlanmıştır

\section{Bulgular}

Postmortem Kalp Okulu 15-16 Eylül 2018 tarihlerinde PAÜTF tarafından Denizli'de gerçekleştirilmiştir. Kursa ülkemizdeki farklı illerde adli tıp alanında eğitim gören 23 uzmanlık öğrencisi katılmıştır. Tüm kurs programa uygun olarak gerçekleştirilmiş ve kurs akışında herhangi bir aksaklık yaşanmamıştır.

Eğitime katılan 23 kişiden 3'ü ön teste katılamadığından bu kişilerin son testleri de değerlendirmeye alınmamıştır. Katılımcıların kurs sonundaki bilgi seviyesindeki değişimin ön test ortalamas $4,6 \pm 0,94$ puan, son test orta-

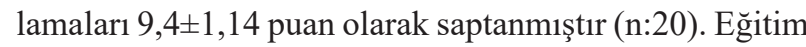
sonrası ortalamaların, eğitim öncesine göre istatistiksel olarak anlamlı şekilde yükseldiği saptanmıştır $(\mathrm{p}<0.001)$. SETh kısa interaktif kurs değerlendirme ölçeği sonuçları incelendiğinde; katılımcıların büyük çoğunluğunun eğitim sürecinden memnun kaldığı görülmektedir. Ayrıca beceri eğitimine yönelik düşüncelerini içeren son iki maddeden eğitim sonrasında kalp diseksiyonu becerisi açısından kendilerini yeterli hissettikleri anlaşılmıştır (Tablo 2). Ölçekten elde edilen sonuçlar için iç tutarlık hesaplanmış ve sonuçlarımızın güvenirliğinin ve geçerliliğinin yüksek olduğu görülmüştür (Cronbach alfa:0.886).

\section{Nitel Değerlendirme Sonuçları;}

"Kursla ilgili olarak eklemek istediğiniz diğer tüm düşünce ve yorumlarınızı yazınız" başlığıyla kurs sonunda alınan yazılı geri bildirimler tek tek okunmuş ve "genel, eğitim süreci ve öğrenme materyali, şikâyetler ve öneriler” şeklinde gruplandırılmıştır. Bu başlıklarda elde edilen sonuçlar ve geri bildirimlere ait örnek cümleler aşağıda sunulmuştur.

\section{A. Genel:}

Katılımcılar, adli tıp uzmanlık eğitimleri sürecinde bu tarz yoğunlaştııılmış uygulamalı eğitimlerin faydalı olacağını, bu eğitimin de gelecekte yapacakları adli tıp uygulamaları için faydalı olduğunu belirtmişlerdir. 
Tablo 2. SETh kısa interaktif kurs değerlendirme ölçeği ve sonuçları. (19 ve 20. maddeler bu araştırma için eklenmiş̧ir.)

\begin{tabular}{|c|c|c|c|c|c|}
\hline & 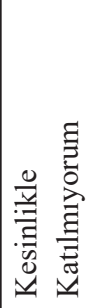 & 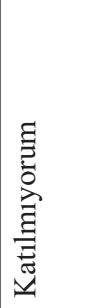 & 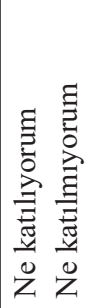 & 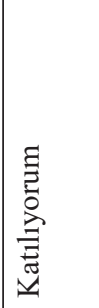 & 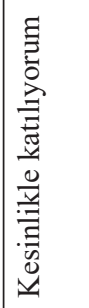 \\
\hline 1. Duyuruda bilmek isteyeceğim her şey vard1 & & 2 & 5 & 6 & 10 \\
\hline 2. Bu kurs için harcadığım zamana değdi & & & & 4 & 19 \\
\hline 3. Katılımcılar olaya hızla dahil olabildiler & & & & 8 & 15 \\
\hline 4. Benim bakış açıma değer verildiğini hissettim & & & & 5 & 18 \\
\hline 5. Bu kursa katılmakla konuya bakış açım değişti & & & 3 & 5 & 15 \\
\hline 6. Verilen bilgiyi özümsemeye yeterli zaman vard1 & & & 1 & 9 & 13 \\
\hline 7. Desteklendiğimi hissettim & & & & 6 & 17 \\
\hline 8. Kurs neleri bildiğimi anlamama yardım etti & & & 1 & 9 & 13 \\
\hline 9. Kurs neleri bilmem gerektiğini anlamama yardım etti & & & 1 & 6 & 16 \\
\hline 10. Kurs bu konudaki davranışımı değiştirmemi sağlayacaktır & & & & 8 & 15 \\
\hline 11. Kurs ihtiyaçlarım hakkındaki düşüncelerimi değiştirdi & & & 4 & 10 & 9 \\
\hline 12. Artık bu konu hakkında daha çok şey bilmek istiyorum & & 1 & 1 & 7 & 14 \\
\hline 13. Bu kurstan zevk aldım & & & 1 & 3 & 19 \\
\hline 14. Eğiticiler tüm öğrencilerin katılımını sağlayabildiler & & & 1 & 9 & 13 \\
\hline 15. Eğiticiler çatışmalarla baş edebildiler* & & & 2 & 6 & 14 \\
\hline 16. Eğiticiler bu kursun hedefine ulaşmasına yardımcı olabildiler & & & & 10 & 13 \\
\hline 17. Eğitici seçimi uygundu & & & 3 & 10 & 10 \\
\hline 18. Kursun başlangıcındaki beklentilerim karşılandı & & & 2 & 12 & 9 \\
\hline $\begin{array}{l}\text { 19. Bundan böyle kalp diseksiyonunda eskisine nazaran daha yetkin } \\
\text { olacağımı düşünüyorum }\end{array}$ & & & & 7 & 16 \\
\hline $\begin{array}{l}\text { 20. Bundan böyle tek başıma kalp diseksiyonu işlemini uygun şekilde } \\
\text { yapabileceğimi düşünüyorum }\end{array}$ & & & 1 & 5 & 17 \\
\hline
\end{tabular}

* Katılımcılardan biri bu kısmı boş bırakmıştır.

"Benzer konularda bu tarz eğitimlerin, güncel kalabilmek adına meslek hayatı boyunca devam etmesini temenni ederim."

"Kurs içeriği genel itibariyle beklentilerimi karşıladı, ileriki meslek hayatımda çok faydalanacağımı düşünüyorum."

"Bu kursun organizasyonu ve eğitim içeriği ihtiyaçlarımızı karşılar nitelikteydi. Önümüzdeki günlerde bu şekilde butik kurslar düzenlenmesi beni mutlu edecektir."

\section{B. Ĕ̈itim süreci ve öğrenme materyali:}

Yazılı geri bildirim veren tüm katılımcılar eğitimin verimli geçtiğini bildirmişlerdir. Katılımcılar çoğunlukla, eğitim için seçilen konudan, yapılan sunumlardan ve özellikle diseksiyon uygulamasından memnun kaldıkları$\mathrm{n} ı$ belirtmişlerdir.
"Eğitimin özellikle uygulamalı olması çok eğitici ve akılda kalıcı oldu."

"Sabırla herkesin tek tek diseksiyon yapmasına olanak veren bir kurstu ve çok efektif olduğunu düşünüyorum."

\section{C. Şikayetler ve öneriler:}

Katılımcılar eğitimin yapıldığı yer ile konaklama için ayarlanan mekan arasındaki mesafeye yönelik şikayetlerini belirtmişlerdir. Sunumlarda olgu örnekleri üzerinden gidilmesi, anatomi sunumunda maket kullanımı, eğitim öncesinde katılımcılara temel okuma kaynakları sunulması gibi konularda önerileri olmuştur.

"Konaklama yeri olarak kursa daha yakın bir yerin ayarlanması daha iyi olabilirdi." 
"Kurs öncesinde katılımc1lara temel okuma kaynaklar1 önerilebilir. Bu sayede katılımcıların kurs öncesi temel bilgilere ulaşabilir ve bunun yanında oryantasyonları artabilir."

"Anatomi anlatımı maket eşliğinde yapılabilirdi."

"Kardiyoloji dersinde anlatım genel bilgilerin yanında bize yönelik klinik bilgi ve olgularla birlikte olabilirdi.”

\section{Tartışma}

Son yıllarda ani kardiyak ölüm tanısı konulmasında yapılan hataların önemini ve bu hataların giderilmesinde eğitimin rolünü vurgulayan birçok çalışma yayınlanmıştır $(5,6)$. Ülkemizde adli tıp uzmanlık eğitimi ve uzmanlık uygulamalarında bir standardizasyon bulunmadığı, özellikle adli olgu etiketi alan ani ölüm olgularında, otopsilerde kardiak patolojilerin değerlendirilmesinde Avrupa Kardiovasküler Patoloji Birliği tarafından ortaya konan standartların yerleşmesi gerektiği belirtilmektedir (9).

$\mathrm{Bu}$ çalışmada ani kardiyak ölümlerin tanısı ve buna yönelik yapılacak otopsilerde kalp diseksiyonu standardizasyonu için hazırlanan Postmortem Kalp Okulu eğitiminin, katılımcıların bilgi ve beceri düzeylerine etkisinin değerlendirilmesi amaçlanmıştır.

Yapılan ön test ve son test ile katılımcıların ani kardiyak ölüm ve kalp diseksiyonu bilgi düzeylerinin, eğitim öncesine göre, istatistiksel olarak anlamlı şekilde artmış olduğu saptanmıştır. Katılımcıların doldurduğu Postmortem Kalp Okulu Değerlendirme Ölçeği'ne göre, katılımcıların eğitim sürecinden ve eğiticilerden memnun kaldıkları, konu hakkındaki bilgi düzeyleri ve ihtiyaçları hakkında farkındalıklarının arttığı, eğitimin kalp diseksiyonu becerilerine olumlu katkısı olduğu belirlenmiştir. $\mathrm{Bu}$ bulgular, farklı tıp branşlarında mezuniyet sonrası tıp eğitimi uygulamalarının değerlendirildiği çalışmalarla benzerlikler göstermektedir (10-12).

Adli Tıp Uzmanları Derneği'nin 2007 yılında yayınladığı Adli Tıp Hizmet Modeli ve İnsan Gücü Planlamasında adli tıp eğitiminde standardizasyonun önemi vurgulanmaktadır (13). Ani kardiyak ölümlerin adli tıp uzmanları tarafından incelenen ölümler arasında büyük yer kapladığı, bu nedenle bu ölümlerin tanınması ve sertifikalandırılmasında çok önemli olduğu, ani kardiyak ölüm olgularında, otopsi sırasında ve sonrasında kardiak patolojilerin ortaya konulmasında yetkin uzmanların görev almasının gerektiği belirtilmektedir $(1,3,9)$. Katılımcıların geri bildirimlerinde, bu eğitim sonrasında ani kardiyak ölüm tanısı ve kalp diseksiyonu becerisi hakkında kendilerini geliştirdikleri, bilgi düzeylerinin arttığı ve bu tarz eğitimlere olan ihtiyaçlarını dile getirdikleri anlaşılmıştır.

Tüm bunların yanında araştırmamızın bazı kısıtlılık- larının da bulunduğunu bildirmekte yarar görmekteyiz. Kursta sadece bilgi seviyesindeki ilerlemenin değerlendirilip, beceri kazanım düzeyinin objektif olarak değerlendirilememiş olması bir kısıtlılık olarak karşımızda durmaktadır. Ancak bu konudaki eksikliğimiz SETh ölçeği sonuna yukarıda detaylarıyla anlatıldığı şekilde iki madde eklenerek giderilmeye çalışılmıştır. Bu sonuçlar incelendiğinde katılımcıların kurs sonunda beceri olarak da gelişme kaydettikleri ve kendilerine güvenlerinin arttığ1 görülmektedir. Kursiyerlerin kurs kazanımlarını gerçek hayatta ne kadar kullanabildikleri konusunun ise uzun dönemde mükerrer kursları takiben araştırılması planlanmıştır.

Sonuç olarak çalışmamızda, adli tıp uzmanlık öğrencilerine uygulanan Postmortem Kalp Okulu eğitiminin, ani kardiyak ölüm ve kalp diseksiyonu bilgi ve beceri düzeylerine kısa dönemde olumlu etkisinin olduğu belirlenmiştir. $\mathrm{Bu}$ eğitimin uzun dönem etkilerinin, ileride yapılacak diğer kurslarla birlikte daha çok katılımcı sayılarıyla beraber değerlendirilmesi planlanmıştır. Ayrıca farklı konularda yapılacak başka programların adli tıp uzmanlık öğrencilerinin eğitimleri için önemli olacağı düşünülmüştür.

\section{Kaynaklar}

1. James JR, Lange RA, Azar OP. What is sudden cardiac death? Acad Forensic Pathol. 2011;1(2):176-186. DOI: https:// doi.org/10.23907/2011.023

2. Kuriachan VP, Sumner GL, Mitchell LB. Sudden cardiac death. Curr Probl Cardiol. 2015 Apr;40(4):133-200. DOI: https://doi.org/10.1016/j.cpcardiol.2015.01.002

3. Basso C, Aguilera B, Banner J, Cohle S, d'Amati G, de Gouveia RH et al. Guidelines for autopsy investigation of sudden cardiac death: 2017 update from the Association for European Cardiovascular Pathology. Virchows Arch. 2017 Dec;471(6):691-705. DOI: https://doi.org/10.1007/s00428017-2221-0

4. Fabre A, Sheppard MN. Sudden adult death syndrome and other non-ischaemic causes of sudden cardiac death. Heart. 2006 Mar;92(3):316-320

5. Wong CX, Brown A, Lau DH, Chugh SS, Albert CM, Kalman JM, Sanders P. Epidemiology of sudden cardiac death: Global and regional perspectives. Heart Lung Circ. 2019 Jan;28(1):6-14. doi: https://doi.org/10.1016/j. hlc.2018.08.026

6. Sheppard MN. Approach to the Cardiac Autopsy. J Clin Pathol. 2012 Jun;65(6):484-495. doi: https://doi.org/10.1136/ jclinpath-2011-200366

7. Al-Khatib SM, Stevenson WG, Ackerman MJ, Bryant WJ, Callans DJ, Curtis AB, et al. 2017 AHA/ACC/HRS guideline for management of patients with ventricular arrhythmias and the prevention of sudden cardiac death: A report of the American College of Cardiology/American 
Heart Association Task Force on Clinical Practice Guidelines and the Heart Rhythm Society. J Am Coll Cardiol. 2018 Oct 2;72(14):e91-e220. doi: https://doi.org/10.1016/j. jacc.2017.10.054

8. Aktürk Z, Dağdeviren N, Şahin M, Özer C. South East Thames (SETh) didaktik ve interaktif kurs değerlendirme ölçeklerinin Türkçe'ye uyarlanması. T Klin Tıp Bilimleri. 2002;22:152-155

9. Koç S, Can M. Birinci basamakta adli tıp, 2. Baskı, 2011

10. Kara CO, Özdemir S. Mezuniyet sonrası cerrahi beceri eğitiminde ölçme değerlendirme. Turkiye Klinikleri J Med Educ-Special Topics 2016;1(2):41-46
11. Yılmaz N, Özgü E, Doğanay M, Aksakal O, Engin-Üstün Y. Jinekolojik cerrahide temel prensipler kursu öntest-sontest değerlendirme sonuçları. Jinekoloji - Obstetrik ve Neonatoloji Tip Dergisi 2018;15(1):14-16

12. Wanzel KR, Matsumoto ED, Hamstra SJ, Anastakis DJ. Teaching technical skills: training on a simple, inexpensive, and portable model. Plast Reconstr Surg. 2002 Jan;109(1):258-263

13. Balcı Y. Adli tıp hizmet modeli ve insan gücü planlamas1, 2007, Adana, http://www.atud.org.tr/wp-content/uploads/2016/07/hizmet_modeli.pdf, (ATUD web sitesi), Erişim tarihi: 20.09.2017 